\title{
A management support framework for subtidal rocky- reef communities on the east coast of Tasmania
}

\author{
Martin P. Marzloff ${ }^{a, b}$, Craig R. Johnson ${ }^{a}$, L. Rich Little ${ }^{b}$, Stewart D. Frusher ${ }^{a}$, Scott D. Ling ${ }^{a}$, Jean- \\ Christophe Souliéc
}

a Institute for Marine and Antarctic Studies, Private Bag 129, Hobart, Tasmania 7001, Australia

${ }^{\mathrm{b}}$ CSIRO Wealth from Ocean Flagship / CSIRO Marine and Atmospheric Research, Castray Esplanade, Hobart, Tasmania 7000, Australia

${ }^{c}$ CIRAD - BIOS «BIOlogical Systems» Department, UMR AGAP - TA-A 108/01, Avenue Agropolis Lavalette, 34398 Montpellier Cedex 5, France

Email: Martin.Marzloff@utas.edu.au

\begin{abstract}
We developed a local and regional scale simulation model of the important dynamical features of seaweed-based rocky reef systems in eastern Tasmania. Climate-driven range extension of the spiny sea urchin (Centrostephanus rodgersii) from Australia's mainland into eastern Tasmanian waters presents a major threat to the productivity of subtidal rocky-reef communities because overgrazing of native seaweed beds by this sea urchin can create and maintain extensive areas of 'barrens' habitat. This causes major loss of production, biodiversity and physical structure. In particular, the two most valuable fisheries in Tasmania, blacklip abalone (Haliotis rubra) and southern rock lobster (Jasus edwardsii), are not commercially viable on C. rodgersii barrens. Additionally, the fishing depletion of large rock lobsters, the main natural predator of $C$. rodgersii, facilitates the establishment of urchin barrens.
\end{abstract}

Based upon empirical observations, field experiments and information about larval dispersal derived from an ocean circulation model, we developed a model that captures the regional dynamics of temperate reef communities on the East coast of Tasmania. Our model is hierarchically structured as a connected network of local models, which can each produce ecosystem shifts from productive kelp bed to sea urchin barrens at the scale of individual reefs. Connectivity between local reefs essentially captures large-scale dispersal of $C$. rodgersii larvae. Through simulations, we test the effectiveness of alternative management options (reduction in lobster fishing, temporary no-take zones as a series of 'rolling closures' and harvesting of the urchin) to minimise the risk of serious ecological impacts of the invasive urchin, i.e. to maintain native reef communities in their original state or restore the productive seaweed habitat from the barren state. Through model forecasts, we assess the trade-off between alternative management strategies in terms of costs and benefits for the fisheries and risks of further sea urchin barrens formation.

Keywords: ecosystem model; larval connectivity; ecosystem effects of fishing; sea urchin barren; southern rock lobster; temperate rocky-reef; management support tool. 


\section{INTRODUCTION}

Sudden and unexpected changes in dynamics are unavoidable for ecological systems under environmental and anthropogenic stresses (Doak et al. 2008). Human exploitation of natural resources requires monitoring and management to maintain long-term ecosystem functioning. Simulation models constitute useful support tools to manage natural resources, especially as the consequences of alternative regulations or management scenarios are difficult if not impossible to assess experimentally at the spatial and temporal scales of ecological dynamics (e.g., Boschetti et al. 2010). Additionally, models can provide valuable support for managers of natural resources by reconciling the scale of ecological dynamics with the scale of management. Spatial heterogeneity often constitutes a key feature of natural communities as a result of variability of ecological dynamics at short temporal and spatial scales (Johnson 2009). This patchiness of ecological communities deserves to be captured realistically, hence at the appropriate scales, in managementsupport tools. However, there are often mismatches between the scale at which these ecological changes occur and the scale of management of human activities that rely on these natural resources.

In eastern Tasmania commercial fisheries are managed at the scale of regional 'blocks' (scale of 100 $\mathrm{km}$ ), while sea urchin can deplete seaweed beds, create and maintain extensive 'barren' areas at the scale of individual reefs (scale of $10^{2}-10^{3} \mathrm{~m}$ ). The barren-forming sea urchin Centrostephanus rodgersii presently represents one of the major threats for Tasmania's subtidal rocky-communities and coastal fisheries (Johnson et al. 2005). First reported in Tasmanian waters in 1978, the long-spined sea urchin C. rodgersii has progressively extended its natural range from New-South-Whales to eastern Tasmania (Ling et al. 2009b). A three-month-long pelagic larval stage has enabled the urchin to spread poleward via climate-driven southwards incursions of the tropical East Australian Current to Tasmania (Ling et al. 2009b). C. rodgersii can create and maintain extensive barrens, which can cover reef areas of c.a. 1-10 ha and reflect dramatic local decline of biodiversity, productivity and habitat structure (Ling 2008). Commercial species, in particular blacklip abalone Haliotis rubra and southern rock lobster Jasus edwardsii that support Tasmania's two most valuable fisheries, decline below harvestable levels on C. rodgersii barrens (Johnson et al. 2005). Rock lobster is the only efficient predator of C. rodgersii in Tasmania (Ling et al. 2009a), but predation is size specific and so populations of supra-legal lobsters (carapace length $>140 \mathrm{~mm}$ ) are essential to naturally control emergent size classes of the urchin in eastern Tasmanian waters (Ling et al. 2009a).

A decision-support tool, which adequately addresses both the spatial dynamics of sea urchin barren formation on the East coast of Tasmania, and the effects of lobster fishing and fisheries regulations on the state of reef communities, is currently lacking. In this paper, we present a framework to support the management of rocky-reef communities in eastern Tasmania. The model is hierarchically structured as a connected network of local models, which each represents the dynamics of individual reefs. The regional dynamics emerge from the combination of these local dynamics and dispersal of larvae between reef patches. Regional connectivity between reefs is derived from a particle-tracking model (called Connie) based upon patterns of surface circulation (Condie et al. 2005).

The objectives of this paper are threefold:

(i) Investigate model sensitivity to the representation of regional processes (essentially larval connectivity between reefs);

(ii) Validate the adequacy of our framework to capture the dynamics of subtidal rocky-reef communities on the east coast of Tasmania, giving particular attention to the pattern of range extension of the long-spined sea urchin and the historical spread of sea urchin barren formation in Tasmanian waters;

(iii) Test alternative management scenarios (e.g., no fishing zones, reduction in lobster fishing mortality, harvesting or culling of the long-spined sea urchin) and assess the tradeoffs between alternative management options in terms of medium and long-term fishery productivity and ecosystem states.

\section{MATERIAL AND METHODS}

The model is structured to capture the regional dynamics of rocky-reef communities at the scale of the East coast of Tasmania emerging from an interconnected network of individual reef patches. 


\subsection{Local model of Tasmanian subtidal rocky-reef communities}

The basal cells in the model capture the general dynamics of local benthic communities at the scale of individual rocky-reefs (area of $10^{2}-10^{5} \mathrm{~m}^{2}$ ). Time in the model is discrete with fortnightly time steps $(26$ per year) as a tradeoff between computational efficiency and consistency of model discrete dynamics with continuous dynamics. Each local model explicitly represents the mean field dynamics of the three following groups:

(i) Seaweed bed. Seaweed bed dynamics (SW for seaweed bed) follows a logistic growth (Eq. 1). Although, a range of herbivorous species rely on macroalgae as a main component of their diet, only sea urchins have demonstrated the ability to deplete Tasmanian seaweed beds through grazing. Thus, the only explicit source of seaweed biomass loss in the model is due to sea urchin grazing.

$$
\mathrm{SW}_{\mathrm{t}+1}=\underbrace{\mathrm{r}_{\mathrm{SW}}}_{\text {Recruitment }}+\underbrace{\mathrm{SW}_{\mathrm{t}} \times \alpha_{\mathrm{SW}} \times \frac{\left(\mathrm{K}_{\mathrm{SW}}-\mathrm{SW}_{\mathrm{t}}\right)}{\mathrm{K}_{\mathrm{SW}}}}_{\text {Logistic population dynamics }}-\underbrace{\beta_{\mathrm{SW}, \mathrm{CR}} \times\left(\sum_{\mathrm{i}=0}^{\mathrm{N}_{\mathrm{CR}}} \mathrm{CR}_{\mathrm{i}, \mathrm{t}}\right)}_{\text {Urchin grazing }},
$$

where $S W_{t}$, indicates seaweed biomass at time t $\left(\mathrm{g} .200 \mathrm{~m}^{-2}\right) ; \mathrm{r}_{\mathrm{SW}}$, seaweed recruitment rate across the reef (density-independent assuming external propagules supply) (g. year ${ }^{-1} .200 \mathrm{~m}^{-2}$ ); $\alpha_{\mathrm{Sw}}$, seaweed intrinsic growth rate $\left(\right.$ year $\left.^{-1}\right) ; \mathrm{K}_{\mathrm{SW}}$, seaweed carrying capacity $\left(\mathrm{g} .200 \mathrm{~m}^{-2}\right) ; \beta_{\mathrm{SW}, \mathrm{CR}}$, sea urchin grazing rate (g. year ${ }^{-1}$. $\left.200 \mathrm{~m}^{-2}\right) ; C R_{i . t}$, biomass of urchin (CR for C. rodgersii) from size class $i$ at time $t\left(\mathrm{~g} .200 \mathrm{~m}^{-2}\right) ; \mathrm{N}_{\mathrm{CR}}$, total number of size classes for the urchin population.

(ii) Long-spined sea urchin. Despite its destructive grazing on seaweed beds, sea urchin population dynamics (CR for Centrostephanus rodgersii; Eq. 2) is independent of seaweed bed dynamics as urchins can forage on micro algae, encrusting algae and drift material to subsist on barren ground in the absence of attached macroalgae. Lobster predation on urchins is size-structured and follows a Holling type-III functional response, providing a parsimonious fit to available data of lobster predation on the long-spined sea urchin.

$$
\begin{aligned}
& \mathrm{CR}_{\mathrm{s}, \mathrm{t}+1}=\mathrm{r}_{\mathrm{CR}}+\mathrm{CR}_{\mathrm{s}, \mathrm{t}} \times \exp \left(-\beta_{\mathrm{CR} \mathrm{s}}\right)+\sum_{\mathrm{j}=1}^{\mathrm{j}<\mathrm{s}}\left(\delta_{\mathrm{s}, \mathrm{j}}^{\prime} \times \mathrm{CR}_{\mathrm{j}, \mathrm{t}}\right)-\left(\sum_{\mathrm{i}>\mathrm{s}}^{\mathrm{N}_{\mathrm{CR}}} \delta_{\mathrm{i}, \mathrm{s}}\right) \times \mathrm{CR}_{\mathrm{s}, \mathrm{t}} \\
& \underbrace{-\beta_{\text {-sR, }} \underbrace{}_{\text {structured predation }}\left(\sum_{\mathrm{CR}}^{\mathrm{N}_{\mathrm{C}}} \mathrm{CR}_{\mathrm{i}, \mathrm{t}}\right)\left(\sum_{\mathrm{i}>\mathrm{m}} \mathrm{RL}_{\mathrm{i}, \mathrm{t}}\right)}_{\text {Size }}-\mathrm{CR}_{\mathrm{s}, \mathrm{t}} \times\left(1-\exp \left(-\mathrm{F}_{\mathrm{CR}_{\mathrm{s}}}\right)\right)^{\prime}
\end{aligned}
$$

where $C R_{s, t}$ represents biomass of sea urchin in size class $s$ at time $t\left(\mathrm{~g} .200 \mathrm{~m}^{-2}\right) ; \mathrm{r}_{\mathrm{CR}}$, urchin recruitment rate (only apply to $\mathrm{CR}_{0}$, i.e. the first size class) (g. year ${ }^{-1} .200 \mathrm{~m}^{-2}$ ); $\delta_{\mathrm{i}, \mathrm{j}}$, 'biomass-based' transition probability from size class $j$ to $i$, or element of the $\mathrm{i}$-th row, $\mathrm{j}$-th column of the transition probability matrix (year ${ }^{-1}$ ). The biomass-based matrix accounts for biomass gain due to individual growth between size class $j$ and $i$; $\delta^{\prime}{ }_{\mathrm{i}, \mathrm{j}}$, 'abundance-based' transition probability from size class $j$ to $i$ (year ${ }^{-1}$ ). The abundance-based matrix is applied to individuals leaving a size class and assumes no change in individual biomass; $\beta_{\mathrm{CR}}$, urchin natural mortality $\left(\right.$ year $^{-1}$ ); $\mathrm{F}_{\mathrm{CR}}$, urchin harvesting mortality (year ${ }^{-1}$ ); $\beta_{\mathrm{CR}, \mathrm{RL}}$, predation rate of lobster following a Holling's typeIII functional response dependent on total urchin biomass density. Predation is size-structured and only lobsters from size classes bigger than $m$ are potential predators of urchins from class $s$. The minimum size threshold for lobsters to physically handle a given size $s$ of urchin is defined after the relationship from Ling et al (2009a) relating lobster carapace length to urchin test diameter.

(iii) Southern rock lobster. Lobster size-structured dynamics is derived from third degree polynomials, which describe individual lobster growth in the Tasmanian southern rock lobster stock assessment model. The population dynamics model was fitted against observations of biomass recovery in Tasmanian marine reserves following protection from fishing.

$$
\mathrm{RL}_{\mathrm{s}, \mathrm{t}+1}=\mathrm{r}_{\mathrm{RL}}{ }^{* 1}+\mathrm{RL} \mathrm{s}_{\mathrm{s}, \mathrm{t}} \times \exp \left(-\beta_{\mathrm{RL}}\right)+\underbrace{\left(\sum_{\mathrm{j}=1}^{(\mathrm{j}<\mathrm{s}}\left(\delta_{\mathrm{s}, \mathrm{j}}^{\prime} \times \mathrm{RL}_{\mathrm{s}, \mathrm{t}}\right)-\left(\sum_{\mathrm{i}>\mathrm{s}}^{\mathrm{N}_{\mathrm{RL}}} \delta_{\mathrm{i}, \mathrm{s}}\right) \times \mathrm{RL}_{\mathrm{s}, \mathrm{t}}\right) * 2}_{\text {Growth between different size classes dependent on seaweed bed state }},(\text { Eq. 3) }
$$


where $R L_{s, t}$, represents biomass of rock lobster from size class $s$ at time $t\left(\mathrm{~g} .200 \mathrm{~m}^{-2}\right) ; \mathrm{r}_{\mathrm{RL}}$, lobster recruitment rate (only apply to $\mathrm{RL}_{0}$, i.e. the first size class) (g. year ${ }^{-1} .200 \mathrm{~m}^{-2}$ ); $\delta_{\mathrm{s}, \mathrm{j}}$, biomass-based transition probability from size class $j$ to $s$, or element of the s-th row, $\mathrm{j}$-th column of the transition probability matrix (year ${ }^{-1}$ or g. $^{-}$ ${ }^{1}$.year ${ }^{-1}$ ); $\delta_{\mathrm{i}, \mathrm{s}}$, abundance-based transition probability from size class $s$ to $i$ (year ${ }^{-1}$ or individual.individual $^{-}$ ${ }^{1}$.year ${ }^{-1}$ ); $S W$, seaweed biomass (g. $200 \mathrm{~m}^{-2}$ ); $\beta_{\mathrm{RL}}$, lobster natural mortality (year ${ }^{-1}$ ); $\mathrm{F}_{\mathrm{RLs}}$, fishing mortality for lobster of class $s$ (year $\left.{ }^{-1}\right)$.

Both lobster recruitment and population productivity are likely to be affected by urchin barren formation (as a result of the loss of both habitat structure facilitating juvenile settlement and primary and secondary productivity). To represent lobster dependency on the state of the seaweed bed, the terms followed by an asterisk * are scaled by the state of the seaweed bed, i.e., multiplied by $\left\lfloor 1-k \times \frac{S W_{t}}{K_{S W}}\right\rfloor$, where $\mathrm{K}_{\mathrm{SW}}$ denotes seaweed carrying capacity $\left(\mathrm{g} .200 \mathrm{~m}^{-2}\right) ; \mathrm{k} \in[0,1]$ defines the dependency of lobster population growth to the state of the seaweed bed ( $k=0$ if no dependency; $k=1$ if full-dependency).

Parameterisation of these equations is essentially derived from empirical and experimental information collected around Tasmania, or alternatively from available literature on similar species or ecosystems. The behaviour of the model of the local dynamics of Tasmanian rocky-reef communities was comprehensively investigated and tested for parameter sensitivity. The local model realistically captures community shifts from dense seaweed bed with a dense macroalgal canopy to $C$. rodgersii barren, and back (Marzloff et al., in preparation). Additionally, to account for the effects of habitat structure (e.g., crevices and boulders facilitate urchin settlement by providing shelter) and depth (e.g., seaweed productivity declines past a given depth) not explicitly captured in the mean field resolution of the local model, some parameters randomly vary through space (i.e., between individual local reefs).

\subsection{Spatial extent and resolution of the model}

The model explicitly represents the dynamics of reef communities on the east coast of Tasmania (Fig. 1). Acoustic habitat surveys completed by SeaMap Tasmania $\subset$ (Tasmanian Aquaculture and Fisheries Institute, University of Tasmania. SeaMap Tasmania 2008) to map shallow reefs were used to map rockyreef habitat potentially under threat of urchin barren formation, so as to define the positioning and the extent of the different local models constituting the basal entities of the regional model.

\subsection{Regional dynamics: definition of larval dispersal between the different reefs}

Regional dynamics in the model emerge from larval connectivity between the different local models. For seaweed beds, propagules are constantly supplied from adjacent and distant reefs and assumed not to limit local recruitment (CR Johnson, pers. comm.). Lobster recruitment is stochastic and independent of local lobster density in the model because of the two following points: 1) rock lobster has a pelagic larval stage of 12-18 months, hence larval dispersal occurs at a much larger scale than the model spatial extent, and 2) the relationship between juvenile settlement and recruitment to the first size class of the lobster population model is challenging to quantify. Dispersal of the 3-month-long pelagic larval stage of C. rodgersii is tractable using ocean current models and is explicitly represented. Explicit representation of regional transport of urchin larvae between reef regions (from their home range in New-South-Whales, or local Tasmanian reefs; see Fig. 2) constitutes an essential driver of the spatial dynamics for the regional model, in particular as the East Australian Current is a key vector of the range extension of C. rodgersii from Australia's mainland to Tasmanian waters.

\section{Particle-tracking with Connie to model urchin larval dispersal}

Larval dispersal of the long-spined sea urchin from the different reefs is explicitly represented and defined by connectivity matrices directly derived from outputs of the particle-tracking software Connie (Condie et al. 2005). 


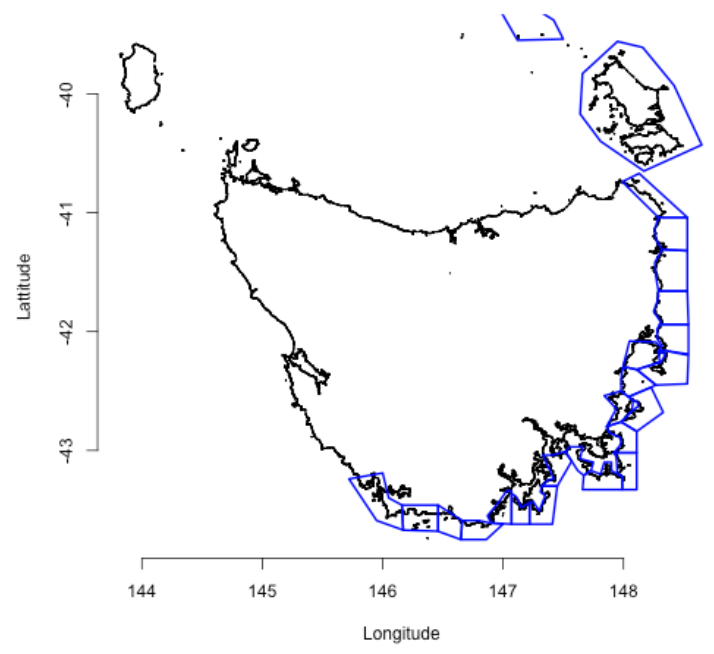

Figure 1. Map of source and sink zones around Tasmania for the particle-tracking simulations with the Connie software. The Kent group zone in Bass Strait extends to the northwest outside the map up to Deal Island. The distribution range of $C$. rodgersii on Australia's mainland is considered as a source zone including all of New-South-Wales coastline down to Point Hicks in southeastern Victoria.

Ocean currents in Connie are estimated from a combination of satellite and tide estimates of sea level heights and modelled surface wind fields (Condie et al. 2005). Current velocities in the model result from the sum of large-scale geostrophic flow computed from sea level height fields, and wind-driven flow using a surface Ekman layer dynamics model and wind fields from the NCEP-NCAR 40 year Reanalysis dataset (see Condie et al. 2005 for more details). The Bluelink Reanalysis, the ocean current model behind Connie, has a 0.1 degrees spatial resolution in latitude and longitude over the study region. The latest version of Connie contains daily outputs from the Bluelink Reanalysis over the period 1993-2007. While Connie's current resolution is fairly limited to capture short-term dispersal processes in shallow coastal waters, the framework is well suited to analyse longer-term (typically more than a week long) meso-scale dispersals of pelagic larvae (Condie et al. 2011). Note also that the model can resolve East Australian Current eddies, which play a key role in determining whether sea urchin larvae reach the Tasmanian coastline or alternatively get carried offshore. The accuracy of the model has been extensively tested against satellite-tracked drifters, and model predictions provide a reliable estimate of outer boundaries of dispersion patterns. Overall, long-term (80-daylong drifts) forecasts by Connie provide reasonable and rather conservative estimates of dispersion, with mean dispersal distances of passive particles underestimated by about $14 \%$ by the software (Condie et al. 2005).

\section{Estimates of urchin larval dispersal}

Particles are uniformly initialised through both space within a specified source zone, and time over a starting period that matches the spawning season of the urchin. C. rodgersii eggs are mostly released in JulyAugust across all of Tasmania's East coast (Ling et al. 2008).

The longevity of the two-armed echinoplutei pelagic larval stage of C. rodgersii is about 90-100 days (Huggett et al. 2005). Little information is currently available about potential diel vertical migration of the larvae through the water column. Passive transport with surface currents is rather likely for C. rodgersii pelagic larvae, which are therefore assumed to disperse within the surface layer of the water column in Connie.

We recognise several sources of uncertainty in Connie's estimates of larval dispersal due to 1) model resolution, 2) imprecise estimates of the longevity and ecology of $C$. rodgersii pelagic larval stage and 3 ) imprecise knowledge of the exact extent and timing of the spawning season. We consider a range of connectivity outputs under different parameterisations to capture the influence of these factors on dispersal estimates. Thus, rather than a single constant strength of connectivity between any source and sink reefs, we defined a probability distribution of connectivity. 


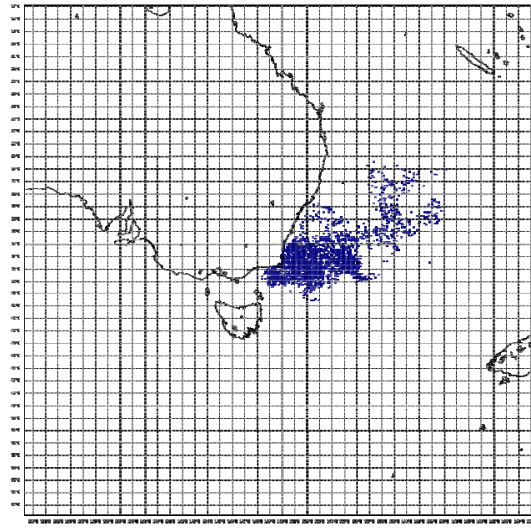

1994

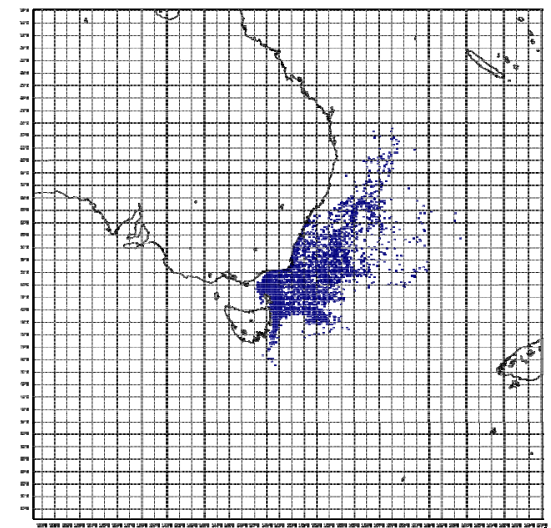

1998

Figure 2. Estimates of $C$. rodgersii larval dispersal with a source zone defined as southeast New-SouthWhales, the native home range of the species. Final positions of 1000 particles from simulations using Connie for two contrasting years: in 1994, the probability of urchin larvae reaching Tasmania is nil, while 1998 was potentially a year of mass recruitment for the urchin with a strong East Australian Current flow carrying larvae from New-South-Whales across Bass Strait to north eastern Tasmania (release period: August, $20^{\text {th }}-$ September, $10^{\text {th }} ; 90$-day longevity; $5 \mathrm{~m}$ depth).

\section{Definition of connectivity in the model}

Regional connectivity between the different rocky-reefs can be represented in different ways:

- The information derived from Connie can be aggregated to represent reef connectivity, and annual connectivity matrices over the available time series (1993-2007) can be used to simulate annual variability in ocean currents carrying urchin larvae. Alternatively, yearly connectivity matrices can be averaged out to define a distribution of connectivity probabilities between the different reefs.

- The resolution of Connie's output is of 0.1 by 0.1 degree thus, each individual cell can include several reefs. We allow the distribution of incoming larvae between adjacent reefs within the same 'sink cell' to either be homogenous or uneven (assuming local retention due to bathymetry or coastal currents).

Sensitivity of model results to alternative representation and formulation of larval dispersal between reefs was explored.

\subsection{Other sources of discrepancies between local models at the scale of the East coast of Tasmania (effect of temperature)}

- Lobster growth rate

Lobster growth rate is highly influenced by temperature and decreases significantly along a southwards gradient in Tasmania, with two annual moults in northern Tasmania against a single one on the south coast. The discrepancies in lobster growth are captured in the local models using the different individual growth functions available from the stock assessment model for each management zone (Punt and Kennedy 1997). Optionally, lobster growth can change through simulation in a given local model with increasing sea surface temperature.

- Urchin larval survival

Warming of coastal waters in eastern Tasmania also facilitates the settlement of the long-spined sea urchin. Indeed, $12^{\circ} \mathrm{C}$ is the lower temperature threshold for C. rodgersii larval development (Ling et al. 2008). In the model, mature $C$. rodgersii populations only produce viable larvae if the temperature is above $12^{\circ} \mathrm{C}$ at the time of spawning (mean for August-September of a given year).

- Temperature data

Sea surface temperature data are available from observations (World Ocean Database 2005 for monthly data) and climate projection models (Climate Futures Tasmania).

\section{PAPER OBJECTIVES}

The following objectives are addressed in this research and will be discussed in my presentation: 
- Accounting for uncertainty in model prediction due to the particle-tracking method defining larval connectivity, and testing for model sensitivity to alternative representations of larval connectivity (i.e., distribution of incoming settlers between adjacent reefs).

- The pattern-oriented model validation (sensu Grimm et al. 2005) essentially consists of comparing the regional dynamics of barren formation evident in simulations, against known history of $C$. rodgersii range extension in Tasmanian waters and the subsequent spread of barren habitat on the East coast of Tasmania (Ling et al. 2009b).

- Finally, the model is used to forecast and assess the trade-offs between fisheries benefits and long-term ecological state of reef communities on the East coast of Tasmania under different management scenarios. Among others, the explicit representation of urchin larval dispersal in the model can help source the key regions supplying urchin larvae to the East coast of Tasmania.

\section{ACKNOWLEDGEMENTS}

The first author is supported by a Ph.D. scholarship co-funded by the joint CSIRO-University of Tasmania program in quantitative marine science (QMS) and the CSIRO Wealth from Ocean flagship, and is also the recipient of an Endeavour International Postgraduate Research (EIPR) scholarship. We are very grateful to Jim Mansbridge and Scott Condie (CSIRO) for generously sharing the code of the Connie software, and Álvaro Roura Labiaga for sharing his precious expertise of the ecology of pelagic larvae.

\section{REFERENCES}

Boschetti, F., A. de La Tour, E. A. Fulton, and L. R. Little. 2010. Interactive modelling for natural resource management. Environmental Modelling \& Software 25:1075-1085.

Condie, S. A., J. V. Mansbridge, and M. L. Cahill. 2011. Contrasting local retention and cross-shore transports of the East Australian Current and the Leeuwin Current and their relative influences on the life histories of small pelagic fishes. Deep-Sea Research Part Ii-Topical Studies in Oceanography 58:606-615.

Condie, S. A., J. Waring, J. V. Mansbridge, and M. L. Cahill. 2005. Marine connectivity patterns around the Australian continent. Environmental Modelling \& Software 20:1149-1157.

Doak, D. F., J. A. Estes, B. S. Halpern, U. Jacob, D. R. Lindberg, J. Lovvorn, D. H. Monson, M. T. Tinker, T. M. Williams, J. T. Wootton, I. Carroll, M. Emmerson, F. Micheli, and M. Novak. 2008. Understanding and predicting ecological dynamics: Are major surprises inevitable? Ecology 89:952961.

Grimm, V., E. Revilla, U. Berger, F. Jeltsch, W. M. Mooij, S. F. Railsback, H. H. Thulke, J. Weiner, T. Wiegand, and D. L. DeAngelis. 2005. Pattern-oriented modeling of agent-based complex systems: Lessons from ecology. Science 310:987-991.

Huggett, M. J., C. K. King, J. E. Williamson, and P. D. Steinberg. 2005. Larval development and metamorphosis of the Australian diadematid sea urchin Centrostephanus rodgersii. Invertebrate Reproduction \& Development 47:197-204.

Johnson, C., S. D. Ling, J. Ross, S. Shepherd, and K. Miller. 2005. Establishment of the long-spined sea urchin (Centrostephanus rodgersii) in Tasmania: first assesment of potential threats to fisheries. Tasmanian Aquaculture \& Fisheries Institute.

Johnson, C. R. 2009. Natural Length Scales of Ecological Systems: Applications at Community and Ecosystem Levels. Ecology and Society 14:21.

Ling, S. D. 2008. Range expansion of a habitat-modifying species leads to loss of taxonomic diversity: a new and impoverished reef state. Oecologia 156:883-894.

Ling, S. D., C. R. Johnson, S. Frusher, and C. K. King. 2008. Reproductive potential of a marine ecosystem engineer at the edge of a newly expanded range. Global Change Biology 14:1-9.

Ling, S. D., C. R. Johnson, S. D. Frusher, and K. R. Ridgway. 2009a. Overfishing reduces resilience of kelp beds to climate-driven catastrophic phase shift. Proceedings of the National Academy of Sciences of the United States of America 106:22341-22345.

Ling, S. D., C. R. Johnson, K. Ridgway, A. J. Hobday, and M. Haddon. 2009b. Climate-driven range extension of a sea urchin: inferring future trends by analysis of recent population dynamics. Global Change Biology 15:719-731.

Punt, A. E., and R. B. Kennedy. 1997. Population modelling of Tasmanian rock lobster, Jasus edwardsii, resources. Marine and Freshwater Research 48:967-980. 